\title{
Clinicopathological significance of HSP70 expression in gastric cancer: a systematic review and meta-analysis
}

\author{
Xiaolu Wang, Li Xie and Lijing Zhu*
}

\begin{abstract}
Background: Heat shock protein 70 (HSP70) has been associated with the clinicopathological characteristics and prognosis of many cancers types, implying that it is a potential cancer biomarker. However, no consensus has been reached regarding its clinicopathological and prognostic significance in patients with gastric cancer. To address this gap, we performed a systematic review and meta-analysis.

Methods: We searched PubMed, Embase, and the Cochrane Library for full-text literature according to the eligibility criteria. We used the odds ratio and hazard ratio as the suitable parameters to evaluate the clinicopathological and prognostic significance of HSP70. The statistical analysis was performed using STATA 15.0.

Results: After inclusion and exclusion of studies based on the eligibility criteria, data of 1,307 patients with gastric cancer from 9 studies were finally included. The pooled outcomes implied that HSP70 expression was significantly correlated with higher differentiation degrees, intestinal gastric cancer, and lymphovascular invasion but not with age, gender, depth of invasion, Helicobacter pylori infection, lymph node invasion, TNM stages, and metastasis. The pooled HR showed no significant correlation between HSP70 expression and overall survival of gastric cancer patients.

Conclusions: Our meta-analysis showed that HSP70 plays a complicated role in the development of gastric cancer. It may be directly engaged in tumour differentiation and distant invasion but cannot be considered a biomarker for predicting the prognosis of gastric cancer.
\end{abstract}

Keywords: Heat shock protein 70, Biomarker, Gastric cancer, Clinicopathological significance, Meta-analysis

\section{Background}

Gastric cancer is one of the most life-threatening cancers, with high incidence and mortality rates worldwide [1]. The estimated number of case reported annually in China is 680,000 , and the incidence rate continues to increase [2]. Despite advances in diagnostic and treatment strategies, the prognosis of patients with advanced gastric cancer remains poor [3]. The 5-year survival rate in patients with stage IV gastric cancer is approximately

\section{*Correspondence: zhulijing@aliyun.com}

The Comprehensive Cancer Centre of Drum Tower Hospital, Medical

School of Nanjing University \& Clinical Cancer Institute of Nanjing

University, Nanjing, China
$4 \%$ [4]. Numerous studies have been conducted to understand the tumour microenvironment of gastric cancers. New biomarker-based treatment methods have shown promising results for improving the prognosis. Therefore, identifying strong biomarkers is important for accurately predicting the clinicopathological features and prognosis of gastric cancer.

Heat shock proteins (HSPs) are indispensable for haemostasis and protection and are produced by cells under stressful conditions. HSPs have been identified as biomarkers in almost all types of cancers including gastric cancer and are known to participate in tumour cell progression, aggressiveness, and treatment resistance [5]. 
They are classified into different families according to their molecular weight. HSP70 belongs to the most abundant family of HSPs and are primarily involved in the folding of denatured proteins. It also inhibits caspasedependent and -independent apoptotic pathways [6, 7]. Increasing evidence has shown that HSP70 is related to the progression and development of various cancers, including cervical carcinoma, bladder urothelial carcinoma, colorectal cancer, and breast cancer [8-11]. Its prognostic effect has been confirmed in some solid tumours such as bladder, breast, and cervical cancers $[12,13]$. Several studies have investigated the relationship between gastric cancer and HSP70 expression; however, the clinicopathological and prognostic significance of HSP70 remain unclear.

Hence, we performed a systematic review and metaanalysis to help resolve this issue. We investigated the correlation between HSP70 expression and the main clinicopathological features of gastric cancer. We also evaluated the prognostic value of HSP70 in patients with gastric cancer.

\section{Methods}

This meta-analysis was performed according to the Preferred Reporting Items for Systematic Reviews and MetaAnalysis [14] and the Meta-analysis of Observational Studies in Epidemiology group guidelines [15].

\section{Search strategy}

PubMed, Embase, and the Cochrane Library were searched for eligible studies by using the following keywords: 'heat shock protein70 OR HSP70' (all fields) AND 'gastric OR stomach' (all fields) AND 'tumor OR tumour OR neoplasm OR cancer OR carcinoma' (all fields). The search was conducted until 10 May, 2021, with no lower date limit. Additionally, the titles, abstracts, and full texts were manually searched using the references of the obtained literature to identify potentially relevant studies.

\section{Inclusion and exclusion criteria}

The eligibility of studies was determined using the following inclusion criteria: 1 ) studies pertaining to gastric cancer and HSP70; 2) studies involving the detection of positive expression of HSP70 without using other biomarkers; 3) inclusion of sufficient data for estimating the prognostic effect of HSP70 and its association with major clinicopathological characteristics of gastric cancer in the original studies; and 4) inclusion of only the latest or most comprehensive study despite the availability of two or more studies investigated the same cohort of patients. The exclusion criteria were as follows: 1 ) animal trials, case reports, reviews, and conference abstracts; 2) articles providing insufficient data for HSP70 expression in gastric cancer.

\section{Data collection and quality assessment}

A Microsoft Office Excel spreadsheet was created to tabulate the following information: author's first name, year, nationality, number of samples, number of patients with positive expression and negative expression of HSP70, detection method, cut-off value, histological information, positive site, outcome statistics with the corresponding 95\% confidence interval (CI), and follow-up information. When an article included both univariate and multivariate analyses, only the latter was used. The quality of each original study was assessed using the Newcastle-Ottawa Scale (NOS) [16], which is based on a 'star system' rated on a scale from 0 (lowest rating) to 9 (highest rating). Eligible studies with more than 6 stars were considered high-quality studies.

\section{Statistical analysis}

ORs with 95\% CI were used to evaluate the relationship between HSP70 expression and clinicopathological characteristics in patients with gastric cancer. To determine the association between HSP70 expression and the prognosis of patients with gastric cancers, HRs with $95 \%$ CIs were used as the summarised estimates. If such data were not directly found in the study and could only be taken from the figures, they were extracted using Engauge Digitizer 4.1 (http://sourceforge.net) from the KaplanMeier survival curves according to the guidelines established by Tierney et al. [17]. The level of heterogeneity among the studies was tested using the $\mathrm{Q}$ and $\mathrm{I}^{2}$ tests. A random-effect model was used to evaluate the data if the $P$ value was $<0.10$ or the $\mathrm{I}^{2}$ value was $>50 \%$. Otherwise, a fixed-effect model was used [18]. Sensitivity analysis was also performed to determine the stability of aggregated results. In case of no substantial variations, our meta-analysis results could be considered stable [19]. The potential for publication bias was detected using the Begg's test and Egger's test. A $P$ value of $<0.05$ was considered to indicate a significant bias. All the analyses were performed using Stata 15.0 (StataCorp LP, College Station, TX, USA).

\section{Results}

\section{Study selection and characteristics}

Of a total of 335 studies initially retrieved from the 3 databases, 252 studies were selected after removing duplicates. The potential studies were screened based on the title, abstract, and publication type, and 238 studies were removed based on the exclusion criteria. Of the remaining 14 studies, 3 studies lacked full texts and 2 studies had investigated the same cohort patients as 
other studies. Finally, 9 studies were included for the meta-analysis [20-28] (Fig. 1). In total, 1307 patients from Jordan, China, Japan, Korea, Germany, and Turkey were included. Nine studies had reported the clinicopathological features of HSP70 [20-28], and 7 studies had investigated the prognostic role of HSP70 [20-25, 27]. Other features of the involved studies are summarised in Table 1. To determine HSP70 expression, 8 studies had used the immunohistochemical analysis [20-23, 25-28], whereas one study [24] had used flow cytometry. The average NOS score was 7.2 (range, 6-8), indicating that the quality of all the studies was good.

\section{Association between HSP70 expression} and the clinicopathological characteristics of gastric cancer Demographic data were collected from each finalised article to calculate the corresponding OR, with 95\% CI showing the HSP70 expression frequency based on different clinicopathological features. These parameters included ages, genders, depth of invasion, differentiation degrees, Helicobacter pylori infection, histological subtypes, lymph node invasion, TNM stages, lymphovascular invasion, and metastasis. Stage I-II tumours were defined as low TNM stages, whereas stage III-IV tumours were defined as high TNM stages. By comparing these ORs with $95 \%$ CI of each clinicopathological feature, we discovered that the positive expression of HSP70 was significantly correlated with a higher differentiation degree $\left(\mathrm{OR}=0.49 ; \quad 95 \% \quad \mathrm{CI}=0.37-0.65 ; \quad P<0.001 ; \mathrm{I}^{2}=0.0 \%\right.$, $P=0$. 479; Fig. 2a; Table 2), intestinal gastric cancer $\left(\mathrm{OR}=2.19 ; 95 \% \mathrm{CI}=1.59-3.01 ; \quad P<0.001 ; \mathrm{I}^{2}=43.0 \%\right.$, $P=0.153$; Fig. 2b; Table 2), and lymphovascular invasion $\left(\mathrm{OR}=1.54 ; 95 \% \mathrm{CI}=1.19-2.00 ; P=0.001 ; \mathrm{I}^{2}=22.9 \%\right.$, $P=0.268$; Fig. 2c; Table 2). However, the results showed a nonsignificant correlation between HSP70 expression and clinical features such as age $(\mathrm{OR}=1.07 ; 95 \%$ $\mathrm{CI}=0.61-1.87 ; P=0.809 ; \mathrm{I}^{2}=0.0 \%, P=0.458 ;$ Fig. $3 \mathrm{a}$; Table 2), sex $(\mathrm{OR}=1.18 ; 95 \% \mathrm{CI}=0.91-1.53 ; P=0.217$;

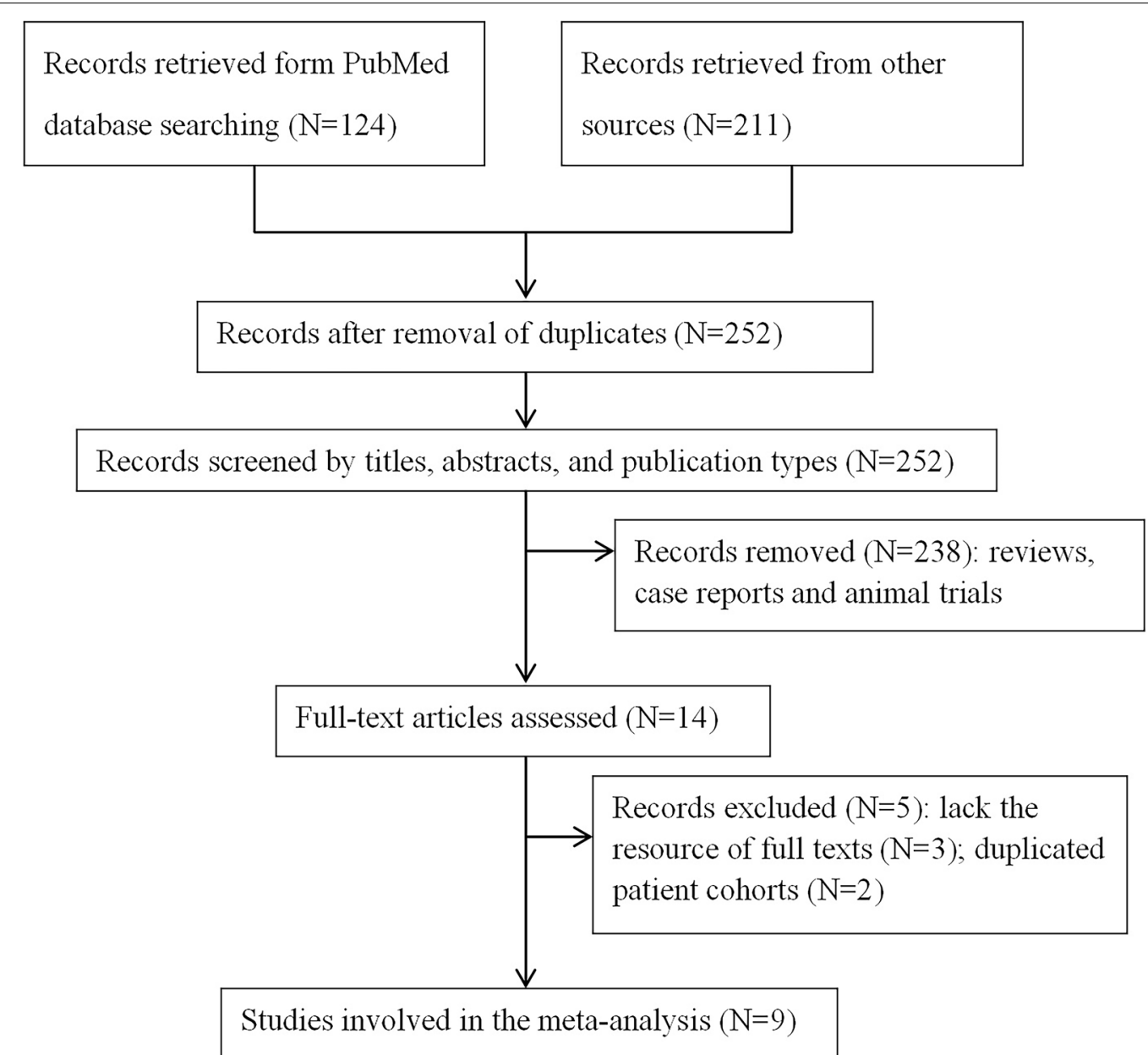

Fig. 1 Flow chart outlining the selection of studies. Ultimately, 9 studies were selected to explore the clinicopathological and prognostic significance in patients with gastric cancer 


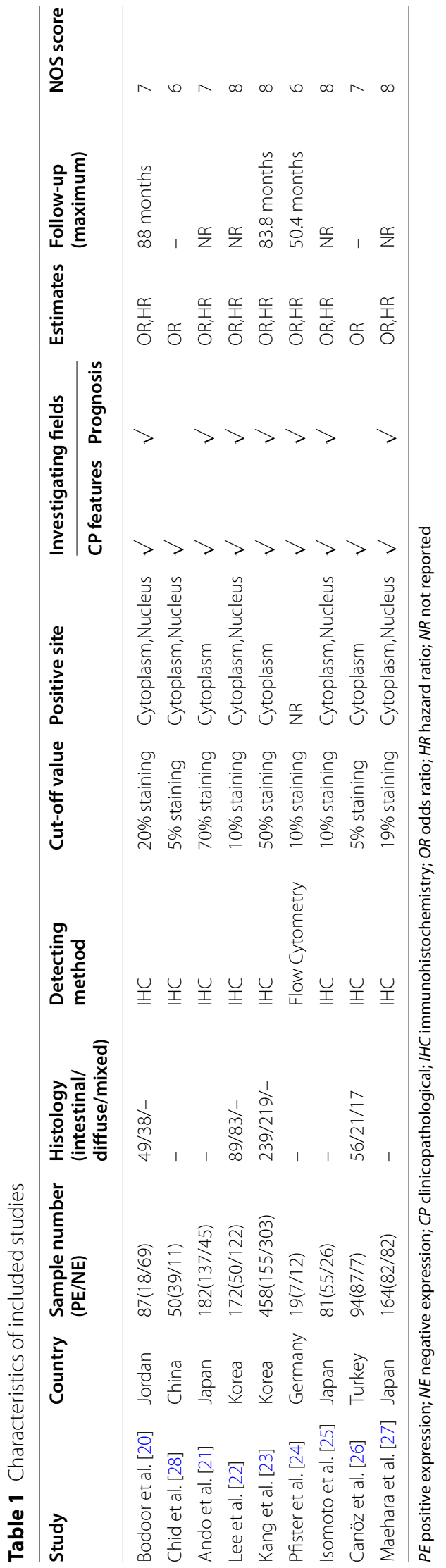




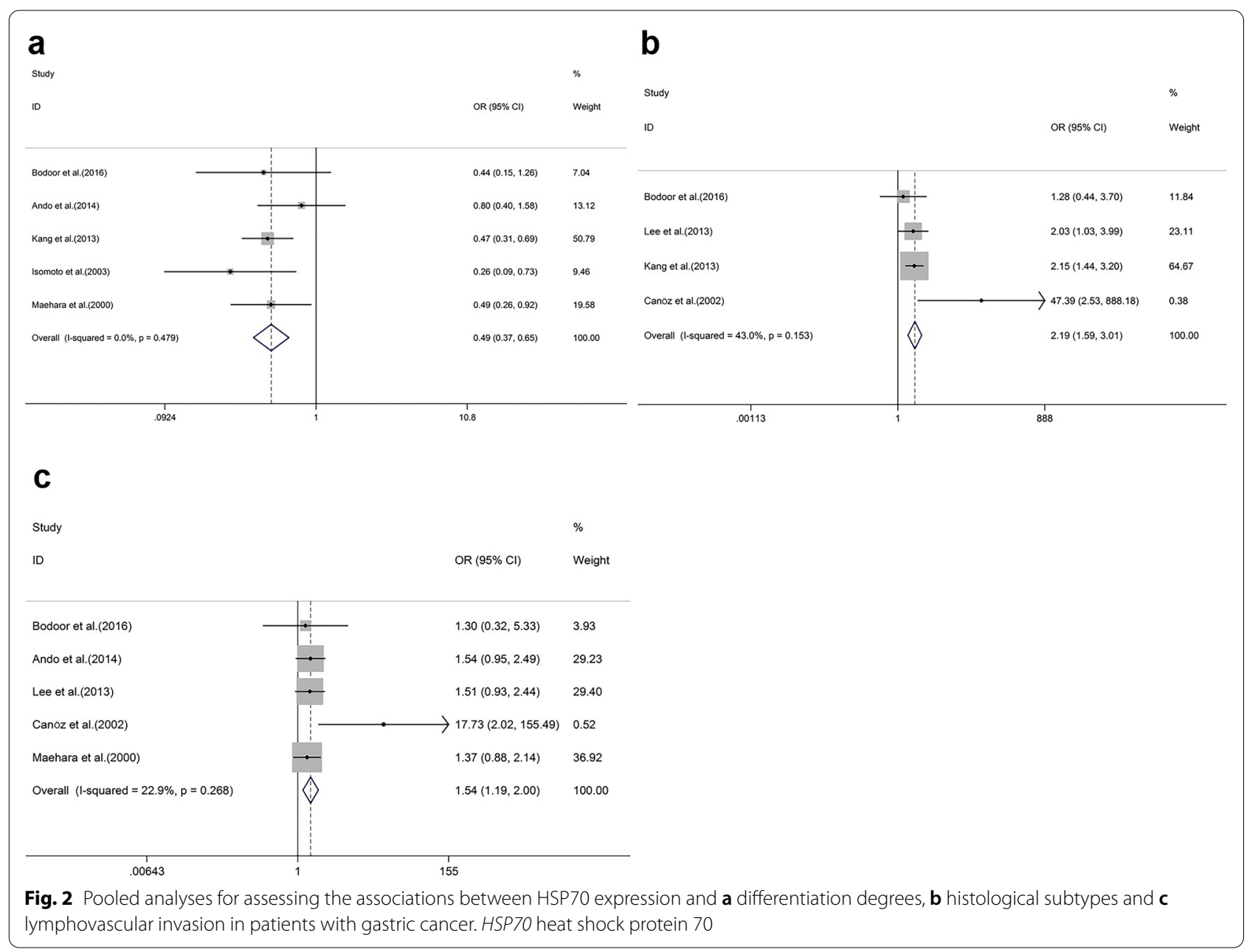

Table 2 Meta-analysis of the clinicopathological significance of HSP70 expression in patients with gastric cancer

\begin{tabular}{|c|c|c|c|c|c|c|}
\hline Clinicopathological features & $\begin{array}{l}\text { Reference } \\
\text { count }\end{array}$ & $\begin{array}{l}\text { Heterogeneity } \\
\text { (I-squared, } p \text { ) }\end{array}$ & Model & OR with $95 \% \mathrm{Cl}$ & $P$ value & Conclusion \\
\hline Age $(\leq 60$ years vs $>60)$ & 2 & $0.0 \%, 0.458$ & Fixed & $1.07(0.61-1.87)$ & 0.809 & Not significant \\
\hline Gender (male vs female) & 8 & $1.0 \%, 0.421$ & Fixed & $1.18(0.91-1.53)$ & 0.217 & Not significant \\
\hline Depth of invasion (T3/T4 vs T1/T2) & 7 & $80.9 \%,<0.001$ & Random & $1.01(0.45-2.30)$ & 0.975 & Not significant \\
\hline Differentiation degrees (low vs high) & 5 & $0.0 \%, 0.479$ & Fixed & $0.49(0.37-0.65)$ & $<0.001$ & Significant \\
\hline H.pylori infection (positive vs negative) & 2 & $48.3 \%, 0.164$ & Fixed & $2.04(0.82-5.03)$ & 0.123 & Not significant \\
\hline Histological subtypes (intestinal vs diffuse) & 4 & $43.0 \%, 0.153$ & Fixed & $2.19(1.59-3.01)$ & $<0.001$ & Significant \\
\hline Lymph node invasion (positive vs negative) & 9 & $74.2 \%,<0.001$ & Random & $1.28(0.72-2.30)$ & 0.399 & Not significant \\
\hline TNM stages (I/II vs II//V) & 6 & $74.2 \%, 0.002$ & Random & $1.15(0.60-2.24)$ & 0.672 & Not significant \\
\hline Lymphovascular invasion (positive vs negative) & 5 & $22.9 \%, 0.268$ & Fixed & $1.54(1.19-2.00)$ & 0.001 & Significant \\
\hline Metastasis (positive vs negative) & 5 & $59.4 \%, 0.043$ & Random & $1.61(0.50-5.25)$ & 0.426 & Not significant \\
\hline
\end{tabular}

HSP7O heat shock protein 70; $O R$ odds ratio; $\mathrm{Cl}$ confidence interval

$\mathrm{I}^{2}=1.0 \%, P=0.421$; Fig. 3b; Table 2), depth of invasion $\left(\mathrm{OR}=1.01 ; 95 \% \mathrm{CI}=0.45-2.30 ; P=0.975 ; \mathrm{I}^{2}=80.9 \%\right.$, $P<0.001$; Fig. 3c; Table 2), H. pylori infection $(\mathrm{OR}=2.04$; 95\% CI $=0.82-5.03 ; \quad P=0.123 ; \quad I^{2}=48.3 \%, \quad P=0.164$;
Fig. 3d; Table 2), lymph node invasion $(\mathrm{OR}=1.28$; $95 \%$ $\mathrm{CI}=0.72-2.30 ; P=0.399 ; \mathrm{I}^{2}=74.2 \%, P<0.001$; Fig. 3e; Table 2), TNM stages $(\mathrm{OR}=1.15 ; 95 \% \mathrm{CI}=0.60-2.24$; $P=0.672 ; \mathrm{I}^{2}=74.2 \%, P=0.002$; Fig. 3 ; Table 2 ), and 


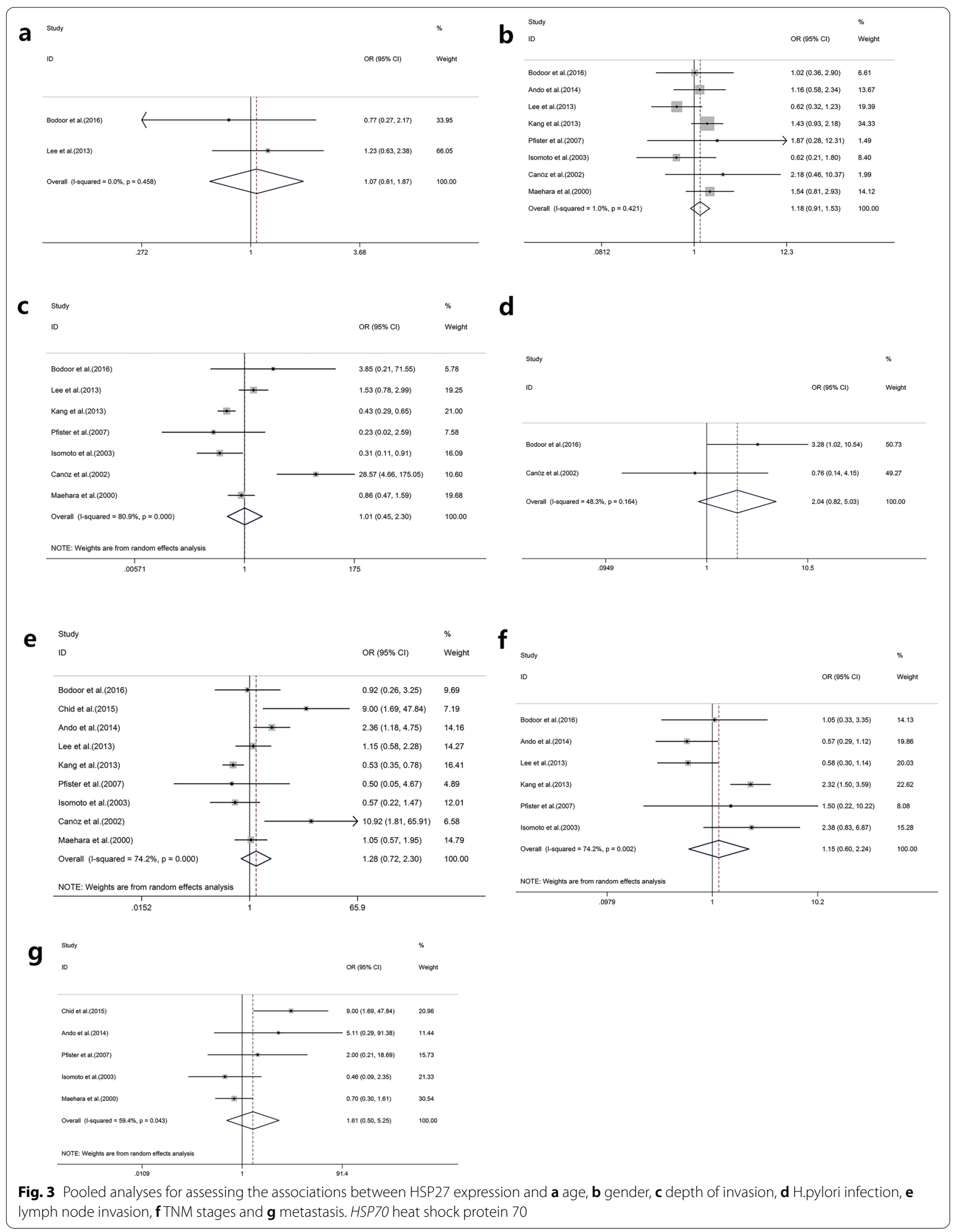


metastasis $\quad(\mathrm{OR}=1.61 ; 95 \% \mathrm{CI}=0.50-5.25 ; \quad P=0.426$; $\mathrm{I}^{2}=59.4 \%, P=0.043$; Fig. 3g; Table 2).

\section{The prognostic value of HSP70 expression in patients with gastric cancer}

The association between HSP70 expression and patient survival had been explored in 7 studies, of which 6 studies had calculated OS [21-25, 27] and one had reported disease-free survival(DFS) [20]. The pooled HR of the former 6 articles was 1.14 (95\% CI $0.89-1.47 ; P=0.3$; $\mathrm{I}^{2}=0.0 \%, P=0.659$; Fig. 4), indicating no significant association between HSP70 expression and overall survival (OS) of patients with gastric cancer. However, further evaluation of the correlation between HSP70 expression and DFS was not pursued because of the lack of adequate number of studies and the availability of results.

\section{Sensitivity analysis}

We performed the sensitivity analyses to determine both the clinicopathological and prognostic significance of HSP70 expression in gastric cancer (the derived forest plots are not shown). Eventually, a slightly high heterogeneity was found only between two studies[21, 28] evaluating the association between HSP70 expression and metastasis $\left(\mathrm{I}^{2}=59.4 \%, P=0.043\right)$. Therefore, the conclusion that the HSP70 expression is not related to metastasis may be unreliable. The strong stability of our meta-analyses for other clinicopathological features and the prognostic value of HSP70 in patients with gastric cancer were confirmed through further sensitivity analyses.

\section{Publication bias}

No evidence for potential publication bias was found in this meta-analysis. The funnel plots obtained from the

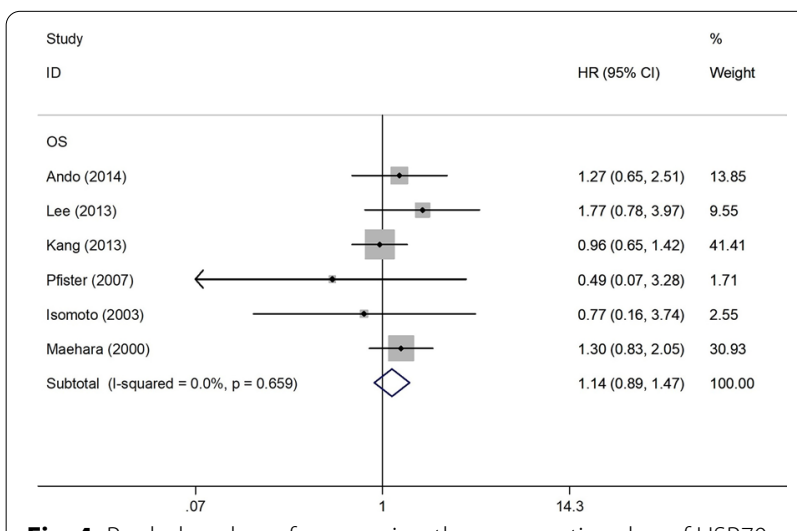

Fig. 4 Pooled analyses for assessing the prognostic value of HSP70 expression for OS in patients with gastric cancer. HSP70 heat shock protein 70 , OS overall survival
Begg's test are shown in Fig. 5, and the corresponding Egger's and Begg's test $P$ values are presented in Table 3. Although no remarkable publication bias was found in our meta-analysis, poor efficacies of both Begg's and Egger's tests were considered because of the scarcity of articles.

\section{Discussion}

Meta-analysis is a well-designed statistical method that combines data from similar articles to derive conclusive findings regarding an uncertain aspect. Predicting the prognosis of gastric cancer is difficult, and only a few biomarkers have been identified so far. To the best of our knowledge, this comprehensive meta-analysis is the first to investigate the relationship between HSP70 expression and the main clinicopathological characteristics of gastric cancer, as well as the role of HSP70 in the prognosis of gastric cancer. Our meta-analysis showed a significant association between HSP70 expression and several pathological features of gastric cancer such as higher differentiation degrees, intestinal gastric cancer, and lymphovascular invasion. However, the pooled results did not exhibit the prognostic value of HSP70 expression in terms of OS of patients with gastric cancer.

HSPs were first discovered in 1962 [29]. They act as molecular chaperones and assist in the folding of proteins under normal metabolic conditions and in amplifying the levels of repair and stabilisation of proteins in the face of molecular stress. In cancer, HSPs maintain homeostasis and promote cancer cell survival by inhibiting apoptotic induction [30,31]. According to the molecular weight, HSPs have been classified into various families such as HSP110, HSP90, HSP70, HSP60, and small heat shock proteins [32]. HSP70 is a high-molecular-weight ubiquitous chaperone protein that regulates the cellular homeostasis by controlling protein folding, translocation, biogenesis, and degradation [33]. HSP70 expression is relatively lower in normal cells than in cancer cells [34]. Ando et al. hypothesised that tumour cells require higher levels of HSP70 than normal cells because of the carcinogenic stresses caused by the overexpression of abnormal oncoproteins and a high level of metabolism [35]. In experimental models, HSP70 overexpression increases the tumourigenicity of transformed cells, whereas HSP70 downregulation reduces the tumourigenicity of these cells [36]. Based on these findings, neutralising HSP70 has become a potential anticancer approach. The inhibitory molecule EGCG, a major flavonoid component of tea that inhibits the activities of HSP90 and HSP70, exhibits an antiproliferative effect on breast cancer cell lines and a xenograft model [37]. In another study, VER-155008 and PES reduced the viability of cancer cells by inhibiting HSP70 expression. VER-155008, an ATP-analogue, 
a

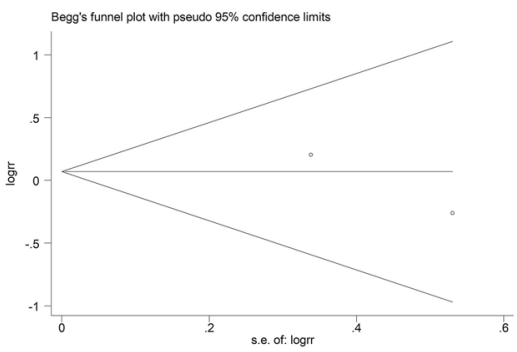

C

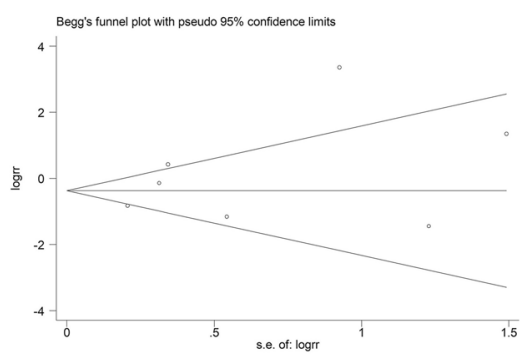

e

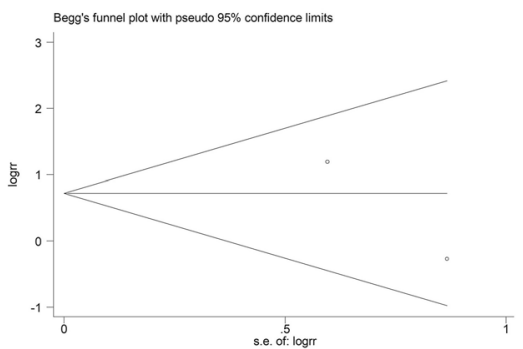

g

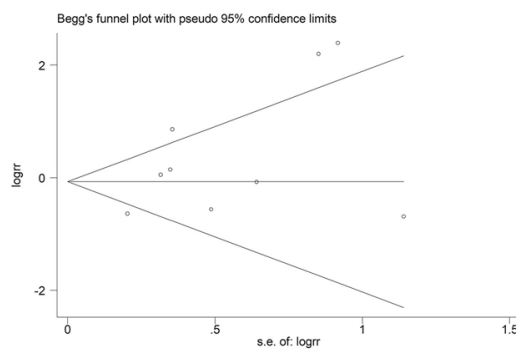

i

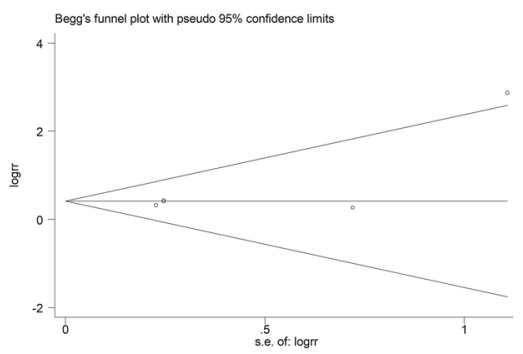

b

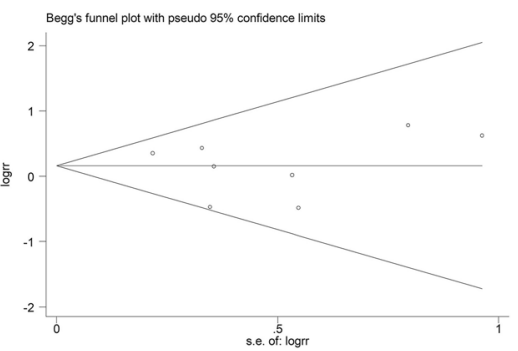

d

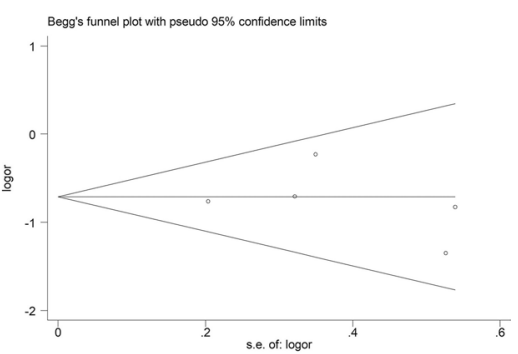

\section{f}

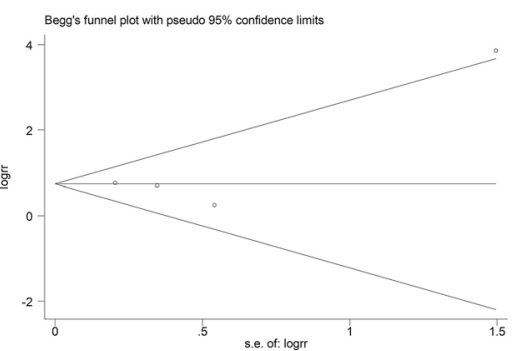

h
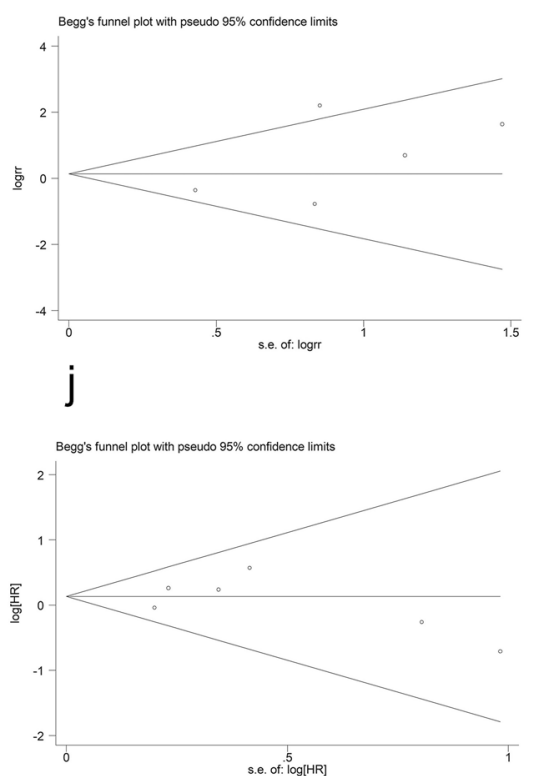

Fig. 5 Funnel plot of studies assessing publication bias of the relationship between HSP70 expression and $\mathbf{a}$ age, $\mathbf{b}$ gender, $\mathbf{c}$ depth of invasion, $\mathbf{d}$ differentiation degrees, e H.pylori infection, $\mathbf{f}$ histological subtypes, $\mathbf{g}$ lymph node invasion, $\mathbf{h}$ metastasis, $\mathbf{i}$ lymphovascular invasion, $\mathbf{j}$ prognostic significance 
Table 3 Evaluations for the potential publication bias within the meta-analysis

\begin{tabular}{|c|c|c|c|c|c|}
\hline Groups of outcomes & $\begin{array}{l}\text { Reference } \\
\text { count }\end{array}$ & Estimates & $\begin{array}{l}\text { Begg's test ( } p \\
\text { value) }\end{array}$ & Egger's test ( $p$ value) & Publication bias \\
\hline Age $(\leq 60$ years vs $>60)$ & 2 & OR with $95 \% \mathrm{Cl}$ & 1.000 & Not reported & Not significant \\
\hline Gender (male vs female) & 8 & OR with $95 \% \mathrm{Cl}$ & 0.536 & 0.786 & Not significant \\
\hline Depth of invasion (T3/T4 vs T1/T2) & 7 & OR with $95 \% \mathrm{Cl}$ & 0.368 & 0.304 & Not significant \\
\hline Differentiation degrees (low vs high) & 5 & OR with $95 \% \mathrm{Cl}$ & 1.000 & 0.745 & Not significant \\
\hline H.pylori infection (positive vs negative) & 2 & OR with $95 \% \mathrm{Cl}$ & 1.000 & Not reported & Not significant \\
\hline Histological subtypes (intestinal vs diffuse) & 4 & OR with $95 \% \mathrm{Cl}$ & 1.000 & 0.493 & Not significant \\
\hline Lymph node invasion (positive vs negative) & 9 & OR with $95 \% \mathrm{Cl}$ & 0.466 & 0.101 & Not significant \\
\hline TNM stages (I/II vs III/IV) & 6 & OR with $95 \% \mathrm{Cl}$ & 1.000 & 0.653 & Not significant \\
\hline Lymphovascular invasion (positive vs negative) & 5 & OR with $95 \% \mathrm{Cl}$ & 0.221 & 0.180 & Not significant \\
\hline Metastasis (positive vs negative) & 5 & OR with $95 \% \mathrm{Cl}$ & 0.221 & 0.295 & Not significant \\
\hline Prognostic significance & 6 & HR with $95 \% \mathrm{Cl}$ & 1.000 & 0.781 & Not significant \\
\hline
\end{tabular}

$O R$ odds ratio; $H R$ hazard ratio; $C l$ confidence interval

binds to the nucleotide-binding site of HSP70, whereas PES interacts with the substrate-binding domain of HSP70 [38]. The synthetic HSP70 inhibitor MAL3-101, a dihydropyrimidine, causes a reduction in the growth of xenotransplanted tumours in mice models, which suggests its role in the treatment of Merkel cell carcinoma [39]. In addition, HSP70 inhibitors have been reported to play a role in eliciting a greater response to neoadjuvant aromatase inhibitor treatment in breast cancer [40]. Despite the success of targeting HSP70 as a potential anticancer therapeutic approach, this strategy has some limitations. For example, because HSP70 is ubiquitously expressed in the physiological environment, its suppression can cause unexpected cytotoxicity in normal cells [36]. Thus, concerted efforts have been made to apply the targeted anticancer immunotherapy based on HSP70 expression.

HSP70 molecules interact with abnormal proteins such as mutated or altered oncogenes and tumour suppressor gene products [41], which are closely related to the progression of gastric cancer. HSP70 upregulation has been observed in tumour tissues and postulated to result from the stressful microenvironment of cancer cells; it might improve tumour cell survival by protecting proteins from degradation [42]. In our study, we reported that HSP70 expression was significantly correlated with the differentiation degree of gastric cancer. HSP70 expression in tumour cells increases in differentiated histiocytic lymphoma cells [43]. Therefore, we can assume that HSP70 is directly engaged in tumour differentiation. Differences in the HSP70 expression may be related to differences in pathogenesis. We also discovered that HSP70 expression was higher in the intestinal type than in the diffuse type of gastric cancer. The intestinal type is regarded to be the consequence of atrophic gastritis and intestinal metaplasia caused by environmental agents. Nevertheless, the diffuse type sometimes develops in the nonatrophic and non-metaplastic gastric epithelium with a strong genetic predisposition [44]. Thus, cancer cells of the intestinal type experience high levels of carcinogenic stress under environmental stimuli, which makes them more dependent on the high expression of HSP70. Finally, we found that HSP70 was correlated with lymphovascular invasion, indicating that HSP70 may be engaged in distant invasion. HSP70 is considered to play a substantial role in the recruitment and differentiation of inflammatory cells. HSP70 can also activate tumour immunity by stimulating innate immune mechanisms and strengthening the cross-presentation of tumour antigens to lymphocytes. Gastric cancer is closely associated with $H$. pylori infection, which can cause chronic inflammation [45]. Although no association between $H$. pylori infection and HSP70 expression was found in our study, an inflammatory microenvironment is believed to increase the HSP70 expression. Consequently, HSP70 was highly expressed in gastric cancer with lymphovascular invasion, playing an important part in tumour progression and metastasis. However, the underlying molecular mechanism remains unclear.

Based on the findings of these studies, some researchers have attempted to determine the potential prognostic significance of HSP70 expression in various types of cancers, including bladder, breast, and cervical cancer, melanoma, and acute myeloid leukaemia [12, 13, 46, 47]. HSP70 is associated with a poor prognosis in bladder, breast, and cervical cancers [12,13]. The positive expression of HSP70 has also been found to be correlated with high metastatic potential and poor prognosis in malignant melanoma [46] and acute myeloid leukaemia [47]. However, a clinical study performed in patients with 
acute myeloid leukaemia demonstrated that patients with a high level of the anti-HSP70 antibody had longer survival [48]. Some studies have explored the potential prognostic significance of HSP70 expression in gastric cancer but reached a contradictory conclusion $[20,22,24,28$, 35]. Incomplete references and differences in prognostic indicators may have considerably affected the accuracy of such studies. Therefore, in our meta-analysis, we used all the available evidence to perform a comprehensive assessment. However, our results did not reveal a significant relationship between HSP70 expression and the survival rate of patients with gastric cancer. The association of HSP70 with higher differentiation degrees, intestinal gastric cancer type, and lymphovascular invasion found in the present meta-analysis implies that HSP70 may play an important role in tumour differentiation and distant invasion. The mechanism of action of HSP70 in the development of gastric cancer is complex, which may partly explain the conclusion that HSP70 expression was not significantly associated with the survival rate of patients with gastric cancer.

In recent years, many studies have focused on exploring the role of HSP70 in GC treatment, and these studies have reported that HSP70 inhibition can enhance the sensitivity of GC cells to thermochemotherapy. The regulatory mechanism may be that Skp2 expression can influence the function of HSP70 [49]. HSP70 has also been reported to be related to apatinib resistance in patients with GC, indicating that apatinib resistance may be overcome by inhibiting HSP70 expression [50]. Furthermore, HSP70 has been considered as a potential therapeutic target and chemosensitiser in GC [51], and it has been developed into HSP vaccines for treating tumours such as melanoma, lymphoma, leukaemia, and glioblastoma [52]. The aforementioned results revealed the potential role of HSP70 in GC treatment. However, the specific mechanism of HSP70 in GC microenvironment remains unclear.

HSP70 may play multiple roles in the pathophysiology of gastric cancer. In cancer, HSPs maintain homeostasis and promote cancer cell survival by inhibiting apoptotic induction [31]. Some critical HSPs intricately regulate the fine balance between protective and destructive immunological responses within the tumour microenvironment [36]. The expression of HSP70 on the surface of tumour cells can confer an immunoregulatory role to this protein by increasing the ability of natural killer cells to lyse tumour cells, thereby improving the prognosis [53]. In addition, whether cancer cells expressing HSP70 on the surface are associated with a positive or negative prognosis may be determined by their metastatic pathways. Because of the limited number of current research samples, a consensus regarding the association between gastric cancer progression and HSP70 expression has not been reached, and it warrants further studies with a large sample size.

\section{Limitations of the study}

The present study has several limitations that must also be considered. First, the sample size in the included studies was small. Second, differences in the ethnic backgrounds of patients with gastric cancer may have contributed to the inaccuracy of our findings. Third, for detecting HSP70 expression in the tumour tissues, different types of immunohistochemical antibodies and cut-off values were used in the included studies that might have contributed to some levels of heterogeneity. Fourth, the potential effect of different adjuvant treatments on gastric cancer patients may have also contributed to the inaccuracy of our results. Fifth, language bias may exist as we only included studies published in English. Sixth, we used Kaplan-Meier survival curves to obtain HRs and 95\% CIs in case the study had not reported these data. In our future study, we aim to derive more convincing data by selecting more eligible studies.

\section{Conclusion}

HSP70 expression is associated with higher differentiation degrees, intestinal gastric cancer type, and lymphovascular invasion. Additionally, HSP70 expression has no association with survival of patients with gastric cancer, which implies that HSP70 may play multiple roles in the pathophysiology of gastric cancer. To overcome the limitations of the present meta-analysis, more large-scale studies using standardised methods are required to be conducted in the future. In addition, studying the underlying mechanisms of HSP70 affecting tumour progression may contribute to the development of novel treatment strategies for gastric cancer. By applying evidence-based methods to more enrolled samples, this meta-analysis can provide insights into the clinicopathological role of HSP70 expression in gastric cancer.

\section{Abbreviations \\ HSP70: Heat shock protein 70; OR: Odds ratio; HR: Hazard ratio; HSPs: Heat shock proteins; NK: Natural killer. \\ Acknowledgements \\ Many thanks for the great help from colleagues at the Comprehensive Cancer Centre of Drum Tower Hospital. \\ Authors' contributions \\ All authors contributed to this work. Study design, writing, constitute figures and tables and data analysis: XW. Screening of abstracts and articles: LX and LZ. Critically reviewing manuscript: $L Z$. All the authors have approved the final version of the manuscript.}

\section{Funding}

Not applicable. 


\section{Availability of data and materials}

All data and materials during this study are presented within the manuscript.

\section{Declarations}

Ethics approval and consent to participate

Not applicable.

\section{Consent for publication}

Not applicable.

\section{Competing interests}

The authors declare that they have no competing interests.

Received: 19 June 2021 Accepted: 22 October 2021

Published online: 22 November 2021

\section{References}

1. Torre LA, Bray F, Siegel RL, Ferlay J, Lortet-Tieulent J, Jemal A. Global cancer statistics, 2012. CA Cancer J Clin. 2015;65:87-108.

2. Chen W, Zheng R, Baade PD, Zhang S, Zeng H, Bray F, et al. Cancer statistics in China, 2015. CA Cancer J Clin. 2016;66:115-32. https://doi. org/10.3322/caac.21338.

3. Wagner AD, Syn NL, Moehler M, Grothe W, Unverzagt S. Chemotherapy for advanced gastric cancer. Cochrane DB Syst Rev (Online). 2017 https://doi.org/10.1002/14651858.CD004064.pub4.

4. Thrumurthy SG, Chaudry MA, Chau I, Allum W. Does surgery have a role in managing incurable gastric cancer? Nat Rev Clin Oncol. 2015;12:676-82.

5. Lianos G, Alexiou G, Mangano A, Mangano A, Rausei S, Boni L, et al. The role of heat shock proteins in cancer. Cancer Lett. 2015;360:114-8.

6. Lazaris AC, Chatzigianni EB, Panoussopoulos D, Tzimas GN, Davaris PS, Golematis BC. Proliferating cell nuclear antigen and heat shock protein 70 immuno-localization in invasive ductal breast cancer not otherwise specified. Breast Cancer Res Tr. 1997;43:43-51.

7. Torronteguy C, Frasson A, Zerwes F, Winnikov E, da Silva VD, Ménoret $A$, et al. Inducible heat shock protein 70 expression as a potential predictive marker of metastasis in breast tumors. Cell Stress Chaperon. 2006;11:34-43.

8. Garg M, Kanojia D, Saini S, Suri S, Gupta A, Surolia A, et al. Germ cellspecific heat shock protein 70-2 is expressed in cervical carcinoma and is involved in the growth, migration, and invasion of cervical cells. Cancer. 2010;1 16:3785-96.

9. Gunaldi M, Kocoglu H, Okuturlar Y, Gedikbasi A, Karabulut M, Alis H, et al. Heat shock protein 70 is a useful marker for predicting colorectal cancer. J BUON. 2015;20:1464-70.

10. Gunaldi M, Afsar CU, Okuturlar Y, Gedikbasi A, Kocoglu H, Kural A, et al. Elevated serum levels of heat shock protein 70 are associated with breast cancer. Tohoku J Exp Med. 2015;236:97-102.

11. Garg M, Kanojia D, Seth A, Kumar R, Gupta A, Surolia A, et al. Heat-shock protein 70-2 (HSP70-2) expression in bladder urothelial carcinoma is associated with tumour progression and promotes migration and invasion. European J Cancer (Oxford, England: 1990). 2010;46:207-15. https:// doi.org/10.1016/j.ejca.2009.10.020.

12. Ciocca D, Calderwood S. Heat shock proteins in cancer: diagnostic, prognostic, predictive, and treatment implications. Cell Stress Chaperones. 2005;10:86-103.

13. Dimas DT, Perlepe CD, Sergentanis TN, Misitzis I, Kontzoglou K, Patsouris $\mathrm{E}$, et al. The prognostic significance of Hsp70/Hsp90 expression in breast cancer: a systematic review and meta-analysis. Anticancer Res. 2018;38:1551-62. https://doi.org/10.21873/anticanres.12384.

14. Liberati A, Altman DG, Tetzlaff J, Mulrow C, Gøtzsche PC, loannidis JPA, et al. The PRISMA statement for reporting systematic reviews and metaanalyses of studies that evaluate healthcare interventions: explanation and elaboration. BMJ. 2009;339: b2700. https://doi.org/10.1136/bmj. b2700.
15. Altman DG, Lausen B, Sauerbrei W, Schumacher M. Dangers of using "optimal" cutpoints in the evaluation of prognostic factors. J Natl Cancer Inst. 1994;86:829-35.

16. Stang A. Critical evaluation of the Newcastle-Ottawa scale for the assessment of the quality of nonrandomized studies in meta-analyses. Eur J Epidemiol. 2010;25:603-5.

17. Tierney JF, Stewart LA, Ghersi D, Burdett S, Sydes MR. Practical methods for incorporating summary time-to-event data into meta-analysis. Trials. 2007;8:16.

18. Higgins JPT, Thompson SG. Quantifying heterogeneity in a meta-analysis. Stat Med. 2002;21:1539-58.

19. Higgins J, Thompson S, Deeks J, Altman D. Measuring inconsistency in meta-analyses. BMJ. 2003;327:557-60

20. Bodoor K, Jalboush SA, Matalka I, Abu-Sheikha A, Haddad Y. Heat Shock protein association with clinico-pathological characteristics of gastric cancer in Jordan: HSP70 is predictive of poor prognosis. Asian Pac J Cancer Prev. 2016;17:3927-35.

21. Ando K, Oki E, Zhao Y, Ikawa-Yoshida A, Kitao H, Saeki H, et al. Mortalin is a prognostic factor of gastric cancer with normal p53 function. Gastric Cancer. 2014;17:255-62

22. Lee H, Lee E, Kim S, Roh M, Jung S, Choi Y. Heat shock protein 70 (HSP70) expression is associated with poor prognosis in intestinal type gastric cancer. Virchows Arch. 2013;463:489-95.

23. Kang $Y$, Jung WY, Lee $H$, Jung W, Lee $E$, Shin BK, et al. Prognostic significance of heat shock protein 70 expression in early gastric carcinoma. Korean J Pathol. 2013;47:219-26.

24. Pfister K, Radons J, Busch R, Tidball J, Pfeifer M, Freitag L, et al. Patient survival by Hsp70 membrane phenotype: Association with different routes of metastasis. Cancer. 2007;110:926-35.

25. Isomoto H, Oka M, Yano Y, Kanazawa Y, Soda H, Terada R, et al. Expression of heat shock protein (Hsp) 70 and Hsp 40 in gastric cancer. Cancer Lett. 2003;198:219-28.

26. Canöz O, Belenli O, Patiroglu T. General features of gastric carcinomas and comparison of HSP70 and NK cell immunoreactivity with prognostic factors. Pathol Oncol Res. 2002;8:262-9.

27. Maehara Y, Oki E, Abe T, Tokunaga E, Shibahara K, Kakeji Y, et al. Overexpression of the heat shock protein HSP70 family and p53 protein and prognosis for patients with gastric cancer. Oncology. 2000;58:144-51.

28. Chid L, Chen Y, Wang J, Zheng C. Proteomics of differentially-expressed proteins between human primary and lymph node metastatic gastric adenocarcinoma. Cancer Res Clin. 2015;27:586-8 and 92.

29. Sadikovic B, Al-Romaih K, Squire J, Zielenska M. Cause and consequences of genetic and epigenetic alterations in human cancer. Curr Genom. 2008;9:394-408.

30. Kimura A, Ogata K, Altan B, Yokobori T, Ide M. Nuclear heat shock protein 110 expression is associated with poor prognosis and chemotherapy resistance in gastric cancer. Oncotarget. 2016;7:18415-23.

31. Rappa F, Farina F, Zummo G, David S, Campanella C, Carini F, et al. HSP-molecular chaperones in cancer biogenesis and tumor therapy: an overview. Anticancer Res. 2012;32:5139-50.

32. Saini J, Sharma PK. Clinical, prognostic and therapeutic significance of heat shock proteins in cancer. Curr Drug Targets. 2017;18:1478-90.

33. Mayer PM. Hsp70 chaperone dynamics and molecular mechanism. Trends Biochem Sci. 2013;38:507-14

34. Sherman MY, Gabai VL. Hsp70 in cancer: back to the future. Oncogene. 2015;34:4153-61.

35. Ando K, Oki E, Yan Z, Kitao H, Saeki H, Ohga T, et al. Significance of mortalin expression in gastric cancer with normal p53. J Clin Oncol. 2012;30:25.

36. Das JK, Xiong X. Heat Shock Proteins in Cancer Immunotherapy. J Oncol. 2019:2019:3267207. https://doi.org/10.1155/2019/3267207.

37. Tran PL, Kim SA, Choi HS, Yoon JH, Ahn SG. Epigallocatechin-3-gallate suppresses the expression of HSP70 and HSP90 and exhibits anti-tumor activity in vitro and in vivo. BMC Cancer. 2010;10:276. https://doi.org/10. 1186/1471-2407-10-276.

38. Schlecht R, Scholz SR, Dahmen H, Wegener A, Sirrenberg C, Musil D, et al. Functional Analysis of Hsp70 Inhibitors. PLoS ONE. 2013;8:78443.

39. Adam C, Baeurle A, Brodsky JL, Wipf P, Schrama D, Becker JC, et al. The HSP70 modulator MAL3-101 inhibits merkel cell carcinoma. PLOS ONE. 2014;9:e92041.

40. Yiu CCP, Chanplakorn N, Chan MSM, Loo WTY, Chow LWC, Toi M, et al. Down-regulation of heat-shock protein 70 (HSP-70) correlated with 
responsiveness to neoadjuvant aromatase inhibitor therapy in breast cancer patients. Anticancer Res. 2010;30:3465-72.

41. All HAE, Rey A, Duvillard P. Expression of heat shock protein 70 and c-myc in cervical carcinoma. Anticancer Res. 1998;18:1533-6.

42. Pratt WB. The role of heat shock proteins in regulating the function, folding, and trafficking of the glucocorticoid receptor. J Biol Chem. 1993;268:21455-8.

43. Marunouchi T, Hosoya H. Regulation of hsc70 expression in the human histiocytic lymphoma cell line, U937. Cell Struct Funct. 1993:18:437-47.

44. Poultsides G, Norton JA. Hereditary diffuse gastric cancer. In: Strong VE, editor. Gastric cancer: principles and practice. Cham: Springer; 2015. p. 251-4.

45. Lochhead P, El-Omar EM. Helicobacter pylori infection and gastric cancer. Med Electron Microsc. 2007;21:281-97.

46. Farkas B, Hantschel M, Magyarlaki M, Becker B, Scherer K, Landthaler M, et al. Heat shock protein 70 membrane expression and melanoma-associated marker phenotype in primary and metastatic melanoma. Melanoma Res. 2003;13:147-52.

47. Gehrmann M, Schmetzer H, Eissner G, Haferlach T, Hiddemann W, Multhoff G. Membrane-bound heat shock protein 70 (Hsp70) in acute myeloid leukemia: a tumor specific recognition structure for the cytolytic activity of autologous NK cells. Haematologica. 2003;88:474-6.

48. Piszcz J, Bolkun Ł, Cichocka E, Galar M, Hołownia A, Kłoczko J. Prognostic relevance of HSP70 antigen and antibody measurement in patients with acute myeloid leukemia of intermediate and unfavorable cytogenetic risk. Pol Arch Med Wewn. 2014;124:165-72.

49. Lei Z, Xia X, He Q, Luo J, Xiong Y, Wang J, et al. HSP70 promotes tumor progression by stabilizing Skp2 expression in gastric cancer cells. Mole Carcinogen (Online). 2021. https://doi.org/10.1002/mc.23346.

50. Teng F, Xu Z, Lyu H, Wang $Y$, Wang L, Huang T, et al. Triptolide reverses apatinib resistance in gastric cancer cell line MKN45 via inhibition of heat shock protein 70. Zhonghua Zhong Liu Za zhi [Chin J Oncol]. 2018;40:928. https://doi.org/10.3760/cma.j.jssn.0253-3766.2018.02.003.

51. Zhai E, Liang W, Lin Y, Huang L, He X, Cai S, et al. HSP70/HSP90-organizing protein contributes to gastric Cancer progression in an autocrine fashion and predicts poor survival in gastric cancer. Cell Physiol Biochem. 2018:47:879-92.

52. Shevtsov M, Multhoff G. Heat shock protein-peptide and HSP-based immunotherapies for the treatment of cancer. Front Immunol. 2016;7:171.

53. Radons J, Multhoff G. Immunostimulatory functions of membrane-bound and exported heat shock protein 70. Exerc Immunol Rev. 2005;11:17-33.

\section{Publisher's Note}

Springer Nature remains neutral with regard to jurisdictional claims in published maps and institutional affiliations.
Ready to submit your research? Choose BMC and benefit from:

- fast, convenient online submission

- thorough peer review by experienced researchers in your field

- rapid publication on acceptance

- support for research data, including large and complex data types

- gold Open Access which fosters wider collaboration and increased citations

- maximum visibility for your research: over 100M website views per year

At BMC, research is always in progress.

Learn more biomedcentral.com/submissions 